\section{Selection of Biologics for Severe Type-2 Asthma}

Yilmaz I

Erciyes University School of Medicine, Department of Chest Diseases, Division of Immunology and Allergy, Kayseri, Turkey

J Investig Allergol Clin Immunol 2019; Vol. 29(5): 399-400 doi: 10.18176/jiaci.0414

Key words: Severe asthma. Atopy. Eosinophil. Nasal polyp. Biologics. Palabras clave: Asma grave. Atopia. Eosinófilo. Pólipo nasal. Biológicos.

\section{To the Editor:}

We read with great interest the report of Sanchez-Jereno et al [1], who reported the first case of severe uncontrolled allergic eosinophilic asthma with the failure of 2 biological therapies (anti-IgE and anti-IL13 monoclonal antibodies $[\mathrm{mAbs}])$ and marked improvement with anti-IL5 mAb. We would like to thank Sanchez-Jereno et al for their contribution to the literature with a case report that suitably addresses the selection of biologics in severe asthma. We would also like to share our clinical experience and opinions on this case report.

The authors state that although several biologics have been approved for uncontrolled severe asthma, no specific biomarkers have been developed to predict a good response to these biologics. However, in the GINA severe asthma guideline published at the end of 2018, suggestions were made on which biologics should be given for the type- 2 high asthma phenotype, and it was emphasized that factors determining the response to treatment should be taken into consideration [2]. Therapy should start with anti-IL5/anti-IL5R mAbs in patients with uncontrolled severe asthma and a blood eosinophils $\geq 300 /$ $\mu \mathrm{L}$. The factors that may predict a good response to anti-IL5/ anti-IL5R biologics are as follows: $(a)$ higher blood eosinophil counts (strongly predictive), (b) more frequent severe exacerbations during the previous year (strongly predictive), (c) adult-onset asthma, and (d) nasal polyposis (treated with maintenance oral corticosteroids [OCS]). Anti-IgE should be started in patients with uncontrolled severe asthma who are sensitized to inhaled allergen(s) in skin prick testing or specific $\operatorname{IgE}$. The factors that may predict a good response to anti-IgE $\mathrm{mAb}$ are as follows: $(a)$ blood eosinophils $\geq 260 / \mu \mathrm{L},(b) \mathrm{FeNO}$ $\geq 20 \mathrm{ppb},(c)$ allergen-driven symptoms, and $(d)$ childhoodonset asthma. The issue to be discussed here is the approach to be adopted if the characteristics that determine the choice of treatment coincide in some patient groups, as in the case reported by the authors. The patient, who had a type- 2 high asthma phenotype, was treated with anti-IL5 mAbs because he had late-onset asthma, nasal polyps, and high eosinophilia. The patient was also given anti-IgE therapy because of atopy and blood eosinophils $\geq 260 / \mu \mathrm{L}$. However, what is important here is whether the patient's atopy status is really appropriate, given the clinical history (childhood allergic asthma, comorbidities such as atopic dermatitis/allergic rhinitis, and respiratory symptoms with exposure to aeroallergens). We think that starting anti-IgE therapy based only on atopy (determination of positivity with skin prick testing and/or determination of specific IgE to common aeroallergens) may not be the ideal approach and that the clinical history should be taken into consideration. In this case, the first-choice biological agent should be an anti-IL5/anti-IL5R mAb owing to the presence of strong predictive markers suggesting a good response to mAbs, such as higher blood eosinophil counts and a higher number of severe exacerbations in the previous year, as well as other predictors such as nasal polyps, late onset, and dependence on OCS $[2,3]$.

Unfortunately, strong evidence for the comparative efficacy and effectiveness of biologics in severe asthma is lacking, since there are no head-to-head studies comparing anti-IgE and antiIL5/anti-IL5R therapy. Data from recent reports on the selection of biologics for severe asthma screened using biomarkers, as well as the GINA recommendations [4-7], indicate that if the main clinical target is to reduce the maintenance dose of OCS, omalizumab should not be the first-choice biologic in patients with OCS-dependent severe eosinophilic asthma [4], because there are no clear data to support reducing OCS in patients treated with omalizumab. However, decreasing the total use of OCS has been shown to facilitate complete weaning from chronic OCS (14\%-50\%) in patients treated with anti-IL5/anti-IL5R mAbs [4,8]. In fact, some patients with eosinophilic asthma require sustained use of OCS to maintain disease control. In any case, long-term use of OCS is associated with significant adverse effects. Bel et al [9] showed that mepolizumab led to a $50 \%$ reduction in OCS dosage in patients with eosinophilic asthma taking chronic OCS. The effects of reduced exacerbations and improved asthma control were maintained despite the reduction.

In eosinophilic asthma with chronic nasal polyposis, the most appropriate biologic would be an anti-IL5/antiIL5R mAb, since the main mechanisms are dysregulation of leukotriene synthesis and chronic epithelial damage and activation by agents such as superantigens and environmental pollutants, which release epithelial cell-derived cytokines such as TSLP, IL-25, and IL-33. These cytokines stimulate type-2 innate lymphoid cell activation, which leads to overproduction of IL-5[10-12]. In our clinic, we also prefer anti IL5/anti-IL5R as the first-choice $\mathrm{mAb}$ in severe eosinophilic asthma (atopic or nonatopic) with nasal polyposis [13].

In conclusion, current or future biologics for severe type2 high asthma should be chosen wisely following logical recommendations, which can currently be made based on the mechanisms of action of the drugs and the underlying pathophysiology of various asthma phenotypes. Unfortunately, 
trials comparing efficacy and combination trials with anti-IgE and anti-IL5/anti-IL5R are lacking and should be performed in the near future.

\section{Funding}

The author declares that no funding was received for the present study.

\section{Conflicts of Interest}

The author declares that he has no conflicts of interest.

\section{References}

1. Sánchez-Jareño $M$, Barranco $P$, Romero $D$, Domínguez-Ortega J, Quirce S. Severe Eosinophilic Allergic Asthma Responsive to Mepolizumab After Failure of 2 Consecutive Biologics. J Investig Allergol Clin Immunol. 2019;29(1):79-81.

2. Adolescent and adults with difficult-to-treat and severe asthma, GINA 2018. www.ginaasthma.org

3. Bleecker ER, Wechsler ME, Fitz Gerald JM, Menzies-Gow A, Wu Y, Hirsch I, et al. Baseline Patient Factor Impact on the Clinical Efficacy of Benralizumab for Severe Asthma. Eur Respir J. 2018;52:1800936.

4. Dávila I, Quirce S, Olaguibel JM. Selection of biologics in severe asthma: a multifaceted algorithm. J Investig Allergol Clin Immunol. 2019;29(4):325-8. doi: 10.18176/jiaci.0398.

5. Froidure A, Mouthuy J, Durham SR, Chanez P, Sibille Y, Pilette C. Asthma phenotypes and IgE responses. Eur Respir J. 2016;47:304-19.

6. Zervas E, Samitas K, Papaioannou Al, Bakakos P, Loukides S, Gaga M. An algorithmic approach for the treatment of severe uncontrolled asthma. ERJ Open Res. 2018;4:001252017.
7. Oishi K, Matsunaga K. Three-step algorithm for biological therapy targeted $\operatorname{lgE}$ and IL-5 in severe asthma. Immun Inflamm Dis. 2018;6(3):374-6.

8. McGregor MC, Krings JG, Nair P, Castro M. Role of Biologics in Asthma. Am J Respir Crit Care Med. 2019;199(4):433-45.

9. Bel EH, Wenzel SE, Thompson PJ, Prazma CM, Keene ON, Yancey SW, et al. Oral glucocorticoid-sparing effect of mepolizumab in eosinophilic asthma. N Engl J Med. 2014;371:1189-97.

10. Brusselle GG, Maes T, Bracke KR. Eosinophils in the spotlight: eosinophilic airway inflammation in nonallergic asthma. Nat Med. 2013;19:977-9.

11. Barnes PJ. Intrinsic asthma: Not so different from allergic asthma but driven by superantigens? Clin Exp Allergy. 2009:39:1145-51.

12. Cahill KN, Boyce JA. Aspirin-exacerbated respiratory disease: Mediators and mechanisms of a clinical disease. J Allergy Clin Immunol. 2017;139(3):764-6.

13. Yilmaz I, Terl M. Asthma management: A new phenotypebased approach using presence of eosinophilia and allergy. Allergy. 2017;72(10):1587-9.

- Manuscript received April 8, 2019; accepted for publication May 7, 2019.

\section{Insu Yilmaz}

Erciyes University School of Medicine

Department of Chest Diseases

Division of Immunology and Allergy

Kayseri, Turkey

E-mail: insu2004@yahoo.com 